\title{
CALL FOR PAPERS - LIBRARY AND INFORMATION RESEARCH SPECIAL ISSUE ON PUBLIC LIBRARIES
}

The journal Library and Information Research (LIR) is seeking papers for a special issue on public libraries, both in the UK and worldwide to be published in April/May 2014. Papers may be either factual reports or peer-reviewed articles and submission details are given below. The final date for submission of papers is Friday $17^{\text {th }}$ January 2014. Please address any queries and expressions of interest to the Guest editor for this issue, Dr John Crawford johncrawford705@yahoo.co.uk

The editorial theme is how public libraries are meeting the challenges of changing attitudes to information and library services and providing services appropriately. Specific topics might include:

- accounts of positive service innovations such as delivering specialised information services (e.g. health or business information), meeting the needs of minority communities, or providing and using new technologies to deliver services;

- areas of controversy such as volunteering, declining numbers of public libraries in the UK and navigating political issues;

- opportunities for cross-sectoral library collaboration, for example between public and academic libraries.

Library and Information Research is the journal of the UK's Library and Information Research Group, but contributions are welcome from practitioners, researchers or others working in fields relating to public libraries in any country.

The journal welcomes:

1. Rigorously written reports describing the development of good practice in an institution or institutions which will be of value to people working in similar areas. These will be subject to referee. Although not of the same standard as research articles report articles should have the following components:

- An introduction setting out the background to the study and the reasons for undertaking it

- A short review of the wider context of the study taking account of similar work elsewhere and some reference to relevant published work. Appropriate bibliographical citations should be provided

- A description of the activity

- Conclusions to be drawn from the study

- How the findings relate to other similar work

- Any recommendations for further action and how the study might inform similar work

2. Research articles, typically of between 2000 and 7000 words, which will be peer reviewed.

\section{Timescales are below}

-Friday 17 January 2014 - submission deadline

- Mid January to mid April 2014 - reviewing and revision process

-April/ May 2013 - target date for publication 


\section{Information for authors}

To find out about writing for Library and Information Research please see the 'Information for Authors', available from the right hand menu bar on the journal home page: http://www.cilipjournals.org.uk/lir.

\section{Submitting a paper to Library and Information Research}

To submit a paper to Library and Information Research you will first need to register with the journal using the 'Register' link at the top of the journal's home page. Please be sure to register both as a reader and an author (there are check boxes for this on the registration page).

Once you have registered you may log in to the journal. You should navigate to the Author Guidelines (via 'Information for authors' as above) and download the template for articles (from the link under 'Manuscript preparation').

When you are ready to submit you should go to your User Home screen and select 'Author'. This will offer you the option to 'Click here to start the submission process'. You will then be taken step by step through the submission process.

If you have any difficulty with submitting your work please contact the Library and Information Research Editor at lirg.LIRteam@gmail.com.

Best wishes

Dr. John Crawford, BA, MA, PhD, FCLIP, FSA (Scot), Independent Libraries Professional,

Chair, Information Skills for a $21^{\text {st }}$ Century Scotland,

And Trustee, Leadhills Heritage Trust,

Home address

21 Polbae Crescent,

Eaglesham,

Glasgow,

G76 0LW

Email johncrawford705@yahoo.co.uk

Information skills for a $21^{\text {st }}$ century Scotland http://scotinfolit.squarespace.com/ View my Linked in profile at http://www.linkedin.com/profile/view?id=105965704 